\title{
Microhabitat Preferences of Biomphalaria pfeifferi and Lymnaea natalensis in a Natural and a Man-made Habitat in Southeastern Tanzania
}

\author{
Jürg Utzinger*/+, Marcel Tanner \\ Department of Public Health and Epidemiology, Swiss Tropical Institute, PO Box, CH-4002 Basel, Switzerland
*Ifakara Health Research and Development Centre, PO Box 53, Ifakara, Tanzania
}

\begin{abstract}
Schistosoma mansoni is an important human parasitic disease which is widespread throughout Africa. As Biomphalaria pfeifferi snails act as intermediate host, knowledge of their population ecology is an essential prerequisite towards understanding disease transmission. We conducted a field study and assessed the density and microhabitat preferences of $\mathrm{B}$. pfeifferi in a natural habitat which was a residual pool of a river. Repeated removal collecting revealed a density of 26.6 [95\% confidence interval (CI): 24.9-28.3] snails $/ \mathrm{m}^{2}$. B. pfeifferi showed microhabitat preferences for shallow water (depths: $0-4 \mathrm{~cm}$ ). They were found most abundantly close to the shoreline (distances: $0-40 \mathrm{~cm}$ ), and preferred either plant detritus or bedrock as substratum. Lymnaea natalensis, a snail which may act as a host for human Fasciola gigantica, also occurred in this habitat with a density of 34.0 (95\% CI: 24.7-43.3) snails $/ \mathrm{m}^{2}$, and preferred significantly different microhabitats when compared to B. pfeifferi. Microhabitat selection by these snail species was also investigated in a man-made habitat nearby, which consisted of a flat layer of concrete fixed on the riverbed, covered by algae. Here, B. pfeifferi showed no preference for locations close to the shoreline, probably because the habitat had a uniform depth. We conclude that repeated removal collecting in shallow habitats provides reliable estimates of snail densities and that habitat changes through constructions may create favourable microhabitats and contribute to additional disease transmission.
\end{abstract}

Key words: Biomphalaria pfeifferi - Lymnaea natalensis - man-made habitat - microhabitat preferences removal collecting - schistosomiasis - Tanzania

Schistosomiasis is a major human parasitic disease widespread throughout Africa and ranks second only to malaria in terms of public health importance (WHO 1993). Schistosomiasis is focally distributed with transmission influenced by several factors, of which intermediate host snail distribution is of great importance. It is well documented that intermediate host snails inhabit a wide range of natural habitats (Webbe \& Jordan 1982, Sturrock 1993, Brown 1994). Often, man-made habitats, such as irrigation canals, pools behind small dams and ponds along roads and railway constructions, may become rapidly inhabited by intermediate host snails, thus contributing to disease transmission (Watson 1958, McCullough

Financial support was granted from the UNDP/World Bank/WHO Special Programme for Research and Training in Tropical Diseases.

${ }^{+}$Corresponding author. Fax: +41-61-271.7951. E-mail: juerg.utzinger@unibas.ch

Received 14 October 1999

Accepted 4 January 2000
1972, Upatham et al. 1981, Betterton 1984, Thomas \& Tait 1984, Betterton et al. 1988, Madsen \& Christensen 1992, Hunter et al. 1993). Habitat features required by the snails are rather grossly described and do not put enough emphasis on the microhabitat (Thomas \& Tait 1984, Madsen et al. 1988, Woolhouse \& Chandiwana 1989), although such knowledge may be relevant for the appropriate design of snail control (Utzinger et al. 1997a).

In the Kilombero district in southeastern Tanzania, schistosomiasis is endemic (Zumstein 1983, Pervilhac et al. 1998). Schistosoma haematobium is the predominant species (Zumstein 1983, Lengeler et al. 1991) and the population ecology of its intermediate host snail, Bulinus globosus (Morelet), has been studied in detail (Marti et al. 1985, Marti 1986). S. mansoni is also present since a first focus was identified in the village of Namwawala in 1984, with an infection prevalence of 39\% among schoolchildren. Subsequent annual chemotherapy of infected schoolchildren had only little effect on the prevalence of $S$. mansoni infection, which suggested a high reinfection rate (Don de Savigny pers. comm.). Later, Biomphalaria pfeifferi (Krauss) snails collected in the Namwawala river were found to release $S$. mansoni cercariae. 
Since control using chemotherapy had failed, control of transmission was tried by environmental modification. A river flushing weir was constructed by having a flat layer of concrete fixed onto the substratum, and building an artificial pool about $20 \mathrm{~m}$ above the weir to impound the water. The weir became operational in 1989 and proved to be effective in reducing the occurrence of $B$. pfeifferi below the weir after flushing (Fritsch 1993). However, the weir has no longer been operated since 1993 and Odermatt (1994) found infected B. pfeifferi snails in the artificial pool above the weir.

There are recent concerns that $S$. mansoni has gained importance in the Kilombero district (Pervilhac et al. 1998) probably because B. pfeifferi has become more widely distributed over the last decade. Given this situation and its relevance for transmission and control of schistosomiasis in the area, we decided to compare the microhabitat preferences of $B$. pfeifferi in a natural habitat with their preferences in a nearby man-made habitat. Repeated removal collecting was used to assess the total snail density. As L. natalensis also occurred abundantly in both habitats, their microhabitat preferences were also investigated and compared with those of B. pfeifferi.

\section{MATERIALS AND METHODS}

Study area - The study was carried out in the Namwawala river which runs through Namwawala village, located in the Kilombero district, Morogoro region in southeastern Tanzania (Fig. 1). The area has a distinct rainy season between December and April, with heavy rains mainly in March and April (Jätzold \& Baum 1968). The mean annual precipitation is $1.300 \mathrm{~mm}$ and the mean annual temperature is $26^{\circ} \mathrm{C}$ (Freyvogel 1960). A detailed description of the river is given by Fritsch (1993) and further details of the village are provided by Smith et al. (1995).

The fieldwork was conducted in two aquatic habitats during the dry season in October 1995 , the period of highest $B$. pfeifferi density (Odermatt 1994). Due to low rainfall in the months preceding the study, both habitats had become isolated, stagnant pools when the investigation was carried out. Site A, a natural habitat, was an isolated residual pool of the Namwawala river that covered an area of $11.75 \mathrm{~m}^{2}$, located approximately $50 \mathrm{~m}$ downstream from where the main road crosses the Namwawala river. Site B, a very shallow man-made habitat of about $10 \mathrm{~m}^{2}$ with a substratum consisting of a flat layer of concrete was connected with the impoundment area of a river flushing weir. Site B is located $10 \mathrm{~m}$ upstream from where the main road crosses the Namwawala river (Fig. 1).

Site A: microhabitat availability - Site A was divided into sections by marking 17 transects, located at right angles to the middle line of the habi-

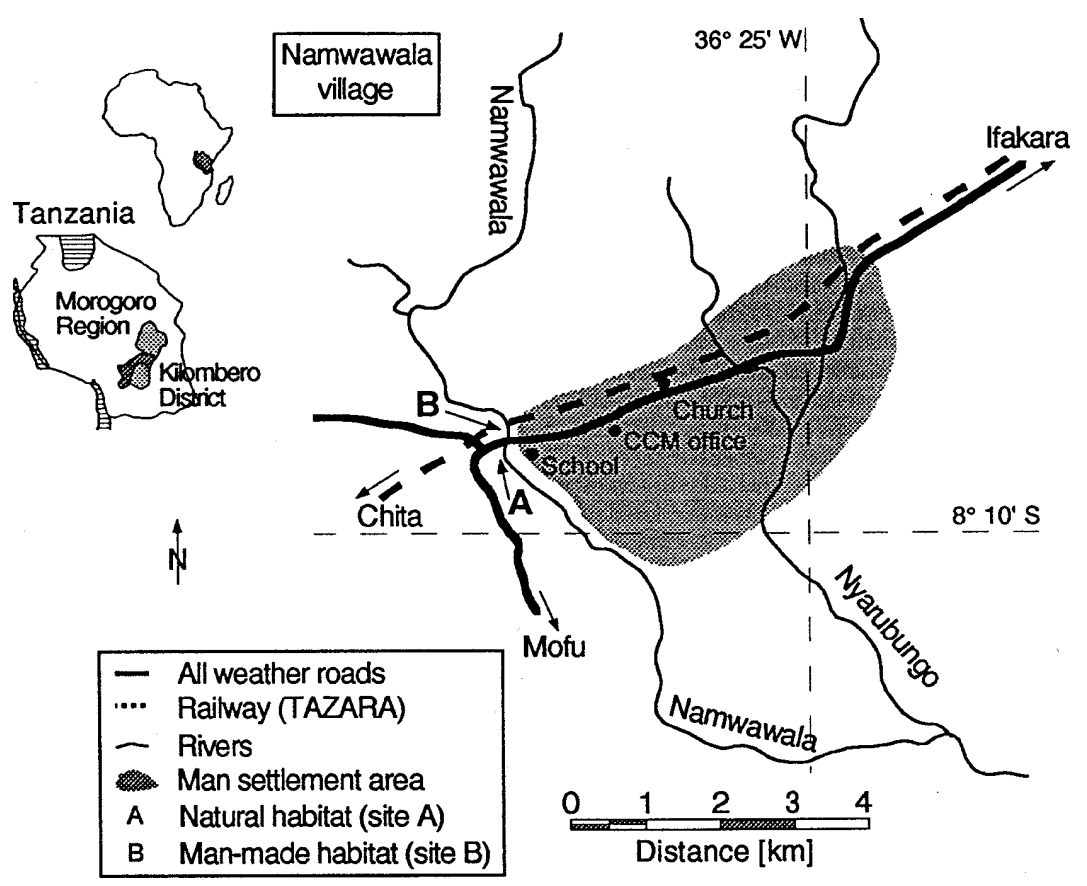

Fig. 1: map of the study area with a natural habitat (site A) and a man-made habitat (site B). 
tat (Bovee 1982). The distance between adjacent transects was set at $50 \mathrm{~cm}$. The width of the river was measured on each transect to the nearest $\mathrm{cm}$. Along the transects, points were selected at every $10 \mathrm{~cm}$. There, microhabitat availability was quantified by measuring the total water column depth with a calibrated stick to the nearest $\mathrm{cm}$ and visually classifying the dominant substratum within an area of $5 \times 5 \mathrm{~cm}$, using the method of De Graaf and Bain (1986) adapted by the authors to meet local conditions: class 1: plant detritus, class 2: clay/silt (0.004-0.06 mm), class 3: sand $(0.07-2.0 \mathrm{~mm})$, class 4: gravel/pebbles $(2.1-64 \mathrm{~mm})$, class 5: cobbles (64.1-250 mm), class 6: boulders (> $250.1 \mathrm{~mm}$ ), and class 7: bedrock. It was found previously that, with experience, such visual classifications were reliable (Utzinger et al. 1997b).

Site A: snail collection - Snails were systematically searched for within the whole habitat, and they were collected by hand, removed and identified at species level. Snail collection was repeated three times on two consecutive days (once on day 1 and twice on day 2). This method allowed calculation of the total density of snails (Sutherland 1996). For each species, the number of snails that were collected and removed during the three consecutive surveys were used to estimate the total population and the catching probability, according to equations provided by Seber and Le Cren (1967). For $B$. pfeifferi the shell diameter, and for $L$. natalensis the shell length, were measured directly in the field to the nearest $0.1 \mathrm{~mm}$, using a calliper.

Site A: microhabitat utilization and preferences - For B. pfeifferi and L. natalensis, the precise location within site A ( $\mathrm{x}$ - and $\mathrm{y}$-axis to the nearest $\mathrm{cm}$ ) was measured and the water column depth above the snails and the dominant substratum at the point of collection recorded. The spatial distribution of both snail species was depicted in a scattergram. Total snail densities [including 95\% confidence interval (CI)] were calculated for different microhabitat types and compared with densities expected in case of equal spatial distribution. When snails were found in a habitat type more frequently or less frequently than expected the terms "habitat preference" and "habitat avoidance" were used, respectively. Comparison of microhabitat availability and utilization by B. pfeifferi and L. natalensis was made by the KolmogorovSmirnov test $(\mathrm{K}-\mathrm{Sm})$ for continuous variables, such as water depth and distance from shoreline, and by chi square test $\left(\chi^{2}\right)$ for substratum (Sokal $\&$ Rohlf 1981).

Site B: microhabitat availability - Along six transects, the water depth and the dominant substratum was recorded systematically at every $10 \mathrm{~cm}$. The water depth was measured with a cali- brated stick to the nearest $0.5 \mathrm{~cm}$ and the substratum was classified as for site A. The distance between adjacent transects was set at $40 \mathrm{~cm}$.

Site B: snail collection - No attempt was made to estimate total snail density because site B was connected with an adjacent pool and immigration and emigration of snails was likely to occur. Snails were collected once in six sections which were set by the transects and had a width of $20 \mathrm{~cm}$.

Site B: microhabitat utilization and preferences - The utilization of microhabitats by $B$. pfeifferi and L. natalensis with respect to water depth, distance from the shoreline and the dominant substratum were recorded. The water column depth above a snail was measured to the nearest $0.5 \mathrm{~cm}$. The dominant substratum and the distance from the closest shoreline was quantified as for site A.

\section{RESULTS}

Site A with a total surface of $11.75 \mathrm{~m}^{2}$ had a water depth that ranged between 0 and $26 \mathrm{~cm}$. The substratum consisted mainly of plant detritus, sand and bedrock. Clay/silt, gravel/pebbles and cobbles were less frequently recorded and boulders were absent from this habitat. Four snail species were collected: B. pfeifferi, L. natalensis, B. globosus and Pila ovata (Peters). The first two species were 15-20 times more abundant than the last two. The total number of snails collected and removed during the three repetitive surveys is given in Table I. Although more B. pfeifferi $(\mathrm{n}=282)$ than L. natalensis snails $(\mathrm{n}=265)$ were collected in the three repeated surveys, the former species was estimated to be less abundant because its catching probability was higher $(0.54$ vs 0.30$)$. This may be explained by the fact that the population of L. natalensis comprised a larger proportion of smallest snails (91 snails with a shell length < $4 \mathrm{~mm}$ ) when compared with B. pfeifferi (27 snails with a shell diameter $<4 \mathrm{~mm}$ ) as shown in Fig. 2a. We estimated the total densities of B. pfeifferi and L. natalensis to be 26.6 (95\% CI: 24.9-28.3) and 34.0 (95\% CI: $25.7-42.4$ ) snails $/ \mathrm{m}^{2}$, respectively.

The spatial distribution of B. pfeifferi and L. natalensis in site A is depicted in Fig. 3. The diagram shows that both species are unevenly distributed within the habitat but tend to prefer similar locations, including those close to the shoreline. These findings are confirmed by analysing microhabitat preferences (Fig. 4). Both snail species were found most abundantly at distances between 0 and $30 \mathrm{~cm}$ from the shoreline. The highest densities of $B$. pfeifferi occurred between 0 and $10 \mathrm{~cm}$ and those of L. natalensis between 20 and $30 \mathrm{~cm}$. The comparison of microhabitat availability in terms of distance from the shoreline and the microhabitat utilization by the two snail species 


\section{TABLE I}

Total number of Biomphalaria pfeifferi and Lymnaea natalensis snails collected and removed in three repetitive surveys with total population estimates and capture probabilities in site A $(\mathrm{CI}=$ confidence interval)

\begin{tabular}{lcc}
\hline & B. pfeifferi & L. natalensis \\
\hline Snails removed in 1. survey & 165 & 115 \\
Snails removed in 2. survey & 84 & 96 \\
Snails removed in 3. survey & 33 & 54 \\
Total snails removed & 282 & 265 \\
Population estimate (95\% CI) & $312(292-332)$ & $400(302-498)$ \\
Catching probability (95\% CI) & $0.54(0.46-0.62)$ & $0.30(0.20-0.41)$ \\
Density: snails $/ \mathrm{m}^{2}$ (95\% CI) & $26.6(24.9-28.3)$ & $34.0(25.7-42.4)$ \\
\hline
\end{tabular}

(a)

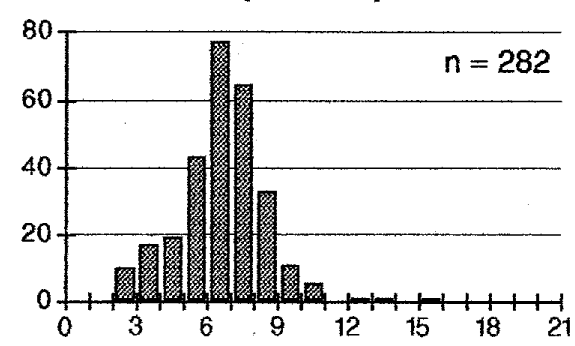

(b)

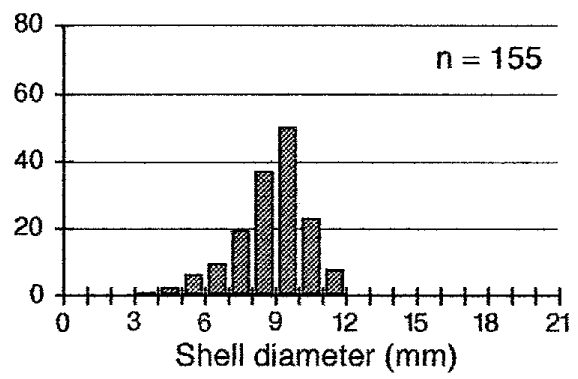

Lymnaea natalensis
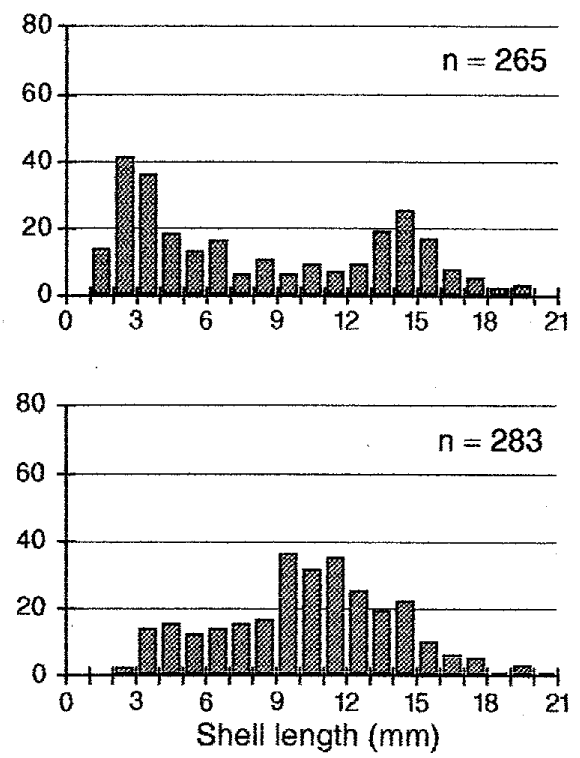

Fig. 2: frequency distribution of size for Biomphalaria pfeifferi and Lymnaea natalensis in site A (a) and site B (b).

revealed statistically significant differences. Site A was a habitat with a mean distance from the shoreline of $38 \pm 22 \mathrm{~cm}$. In this habitat, $B$. pfeifferi were found at a mean distance from the shoreline of $26 \pm 19 \mathrm{~cm}$ (K-Sm test, $\mathrm{P}<0.001)$. L. natalensis were found at a mean distance of $29 \pm 17 \mathrm{~cm}$ (KSm test, $\mathrm{P}<0.001)$.

Both snail species showed microhabitat preferences for shallow water with peak densities observed in water depths between 0 and $4 \mathrm{~cm}$. Comparison between the water depths that were available and preferences shown by B. pfeifferi and L. natalensis revealed statistically significant differences. The mean water depth in site A was $8.3 \pm 7.3 \mathrm{~cm}$, whereas the mean preferred depths of B. pfeifferi and L. natalensis were $2.2 \pm 2.5 \mathrm{~cm}$ $(\mathrm{K}-\mathrm{Sm}$ test, $\mathrm{P}<0.001)$ and $1.5 \pm 1.3 \mathrm{~cm}(\mathrm{~K}-\mathrm{Sm}$ test, $\mathrm{P}<0.001)$, respectively.
The substratum histograms show that B. pfeifferi and L. natalensis prefer either plant detritus (class 1) or bedrock (class 7). As compared with the substratum availability, these differences were statistically significant $\left[\chi^{2}, 5\right.$ degree of freedom (d.f.) $=56.9, \mathrm{P}<0.001$ for $B$. pfeifferi and $\chi^{2}$, 5 d.f. $=99.7, \mathrm{P}<0.001$ for $L$. natalensis $]$.

When microhabitat preferences for $B$. pfeifferi and $L$. natalensis were compared it was found that the two species occurred in significantly different microhabitats. B. pfeifferi preferred deeper water (mean depth: $2.2 \pm 2.5 \mathrm{~cm}, \mathrm{n}=282$ ) than L. natalensis (mean depth: $1.5 \pm 1.3 \mathrm{~cm}, \mathrm{n}=265$, $\mathrm{P}=0.0007, \mathrm{~K}-\mathrm{Sm}$ test) and B. pfeifferi preferred to live closer to the shoreline (mean distance: $26.4 \pm 18.6 \mathrm{~cm}, \mathrm{n}=282$ ) than L. natalensis (mean distance: $28.8 \pm 17.2 \mathrm{~cm}, \mathrm{n}=265, \mathrm{P}=0.023$, K$\mathrm{Sm}$ test). Both species preferred plant detritus and 


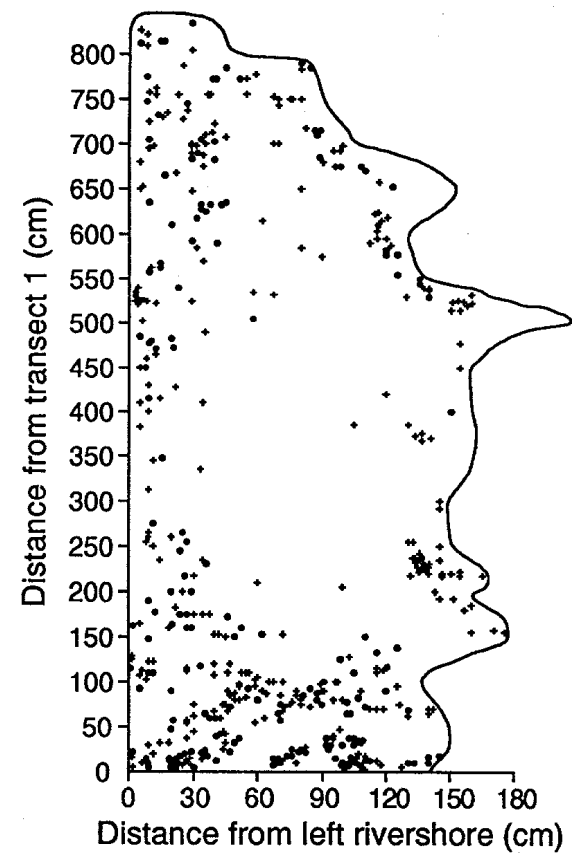

Fig. 3: spatial distribution of 282 Biomphalaria pfeifferi (+) and 265 Lymnaea natalensis $(\bullet)$ snails in site A. bedrock as dominant substrata; however, L. natalensis was more likely to be found on plant detritus and less likely to be found on bedrock $\left(\chi^{2}\right.$, 5 d.f. $=20.6, \mathrm{P}=0.001$ ).

In site $B$, the water depth was uniform and ranged between 0 and $6 \mathrm{~cm}$. The substratum consisted of an artificial layer of concrete that was uniformly covered by algae. During the single survey, a total of 443 snails were found. There were three different species of which L. natalensis was the most abundant at $63.9 \%(283 / 443)$, while B. pfeifferi accounted for $35 \%(155 / 443)$ and B. globosus for $1.1 \%$ (5/443) of all snails.

The frequency distributions of size for B. pfeifferi and L. natalensis are given in Fig. 2b. The spatial distribution of these two snail species with respect to water depth and distance to the closest shore is summarized in Table II. It is characterised by a distinctively different pattern from that in site A: B. pfeifferi showed no preference for habitats closer to the shoreline and instead, were more likely to be found at distances between 101 and $250 \mathrm{~cm}$ from the shoreline.

The comparison between the microhabitat preferences of B. pfeifferi and L. natalensis in site B
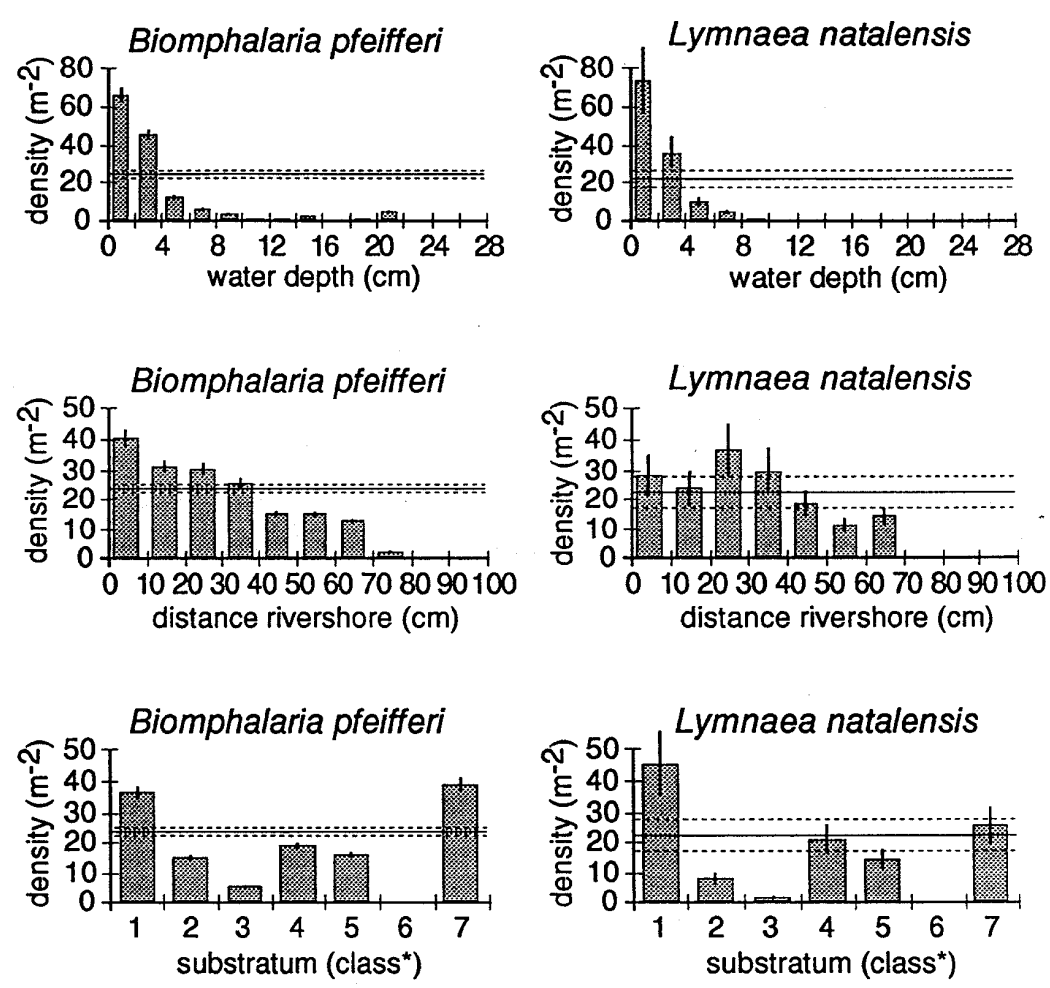

Fig. 4: microhabitat preferences of 282 Biomphalaria pfeifferi and 265 Lymnaea natalensis for water depth, distance from the shoreline and dominant substratum composition in site A. - : mean density in case of equal distribution, ---: lower and upper $95 \%$ confidence interval, |: error bars. Asterisk: plant detritus (class 1), clay/silt (0.004-0.06 mm; class 2), sand (0.07-2 mm; class 3), gravel/pebbles (2.1-64 mm; class 4), cobbles (64.1-250 mm; class 5), boulders (> 250.1 mm; class 6) and bedrock (class 7). 
TABLE II

Characterization of site B, as assessed by a systematic sample $(n=240)$ of water depths and distances from the shoreline, and occurrence of B. pfeifferi $(\mathrm{n}=155)$ and L. natalensis $(\mathrm{n}=283)$ with regard to these two microhabitat features

\begin{tabular}{lcrr}
\hline Microhabitat features & No. of samples & \multicolumn{2}{c}{ No. of snails } \\
\cline { 3 - 4 } & & & B. pfeifferi \\
\hline Water depth & & & \\
$0-1 \mathrm{~cm}$ & 152 & 40 & 240 \\
$1-2 \mathrm{~cm}$ & 40 & 75 & 38 \\
$2-3 \mathrm{~cm}$ & 18 & 38 & 4 \\
$3-4 \mathrm{~cm}$ & 16 & 2 & 0 \\
$4-5 \mathrm{~cm}$ & 7 & 0 & 0 \\
$5-6 \mathrm{~cm}$ & 7 & 0 & 283 \\
\hline Total & 240 & 155 & 110 \\
\hline Distance from shoreline & & & 61 \\
$0-50 \mathrm{~cm}$ & 60 & 15 & 52 \\
$51-100 \mathrm{~cm}$ & 53 & 17 & 34 \\
$101-150 \mathrm{~cm}$ & 50 & 38 & 26 \\
$151-200 \mathrm{~cm}$ & 46 & 46 & 283 \\
$201-250 \mathrm{~cm}$ & 31 & 39 & \\
\hline Total & 240 & 155 & \\
\hline
\end{tabular}

revealed significant differences. B. pfeifferi occurred in deeper water than L. natalensis (mean depth: $1.3 \pm 0.8 \mathrm{~cm}, \mathrm{n}=155$; compared with $0.3 \pm 0.6 \mathrm{~cm}, \mathrm{n}=283, \mathrm{P}<0.0001 ; \mathrm{K}-\mathrm{Sm}$ test $)$ and tended to live further away from the shoreline than L. natalensis (mean distance: $151 \pm 62 \mathrm{~cm}$, $\mathrm{n}=155$; compared with $89 \pm 68 \mathrm{~cm}, \mathrm{n}=283$, $\mathrm{P}<0.0001, \mathrm{~K}-\mathrm{Sm}$ test).

\section{DISCUSSION}

The present study allowed us to compare estimates of the total density of $B$. pfeifferi which we calculated from data on three consecutive samples with published results based on other quantitative methods, such as mark-recapture or exhaustive sampling in a given area. Total density measures of intermediate host snails of schistosomiasis are important variables which may affect the transmission rates of the disease (Woolhouse 1992). Interestingly, our density estimates of $26.6 \mathrm{~B}$. pfeifferi snails $/ \mathrm{m}^{2}$ is similar to those of $16-51$ snails $/ \mathrm{m}^{2}$ obtained by Thomas and Tait (1984) using the mark-recapture method. A peak density of 98 snails $/ \mathrm{m}^{2}$ was reported by Woolhouse (1992), also using the mark-recapture method. Using $25 \mathrm{~cm}^{2}$ quadrats, peak densities of $83 \pm 23$ snails $/ \mathrm{m}^{2}$ were estimated by Thomas and Tait (1984). Our mean and peak density ranged in the same magnitude, indicating that estimates based on repetitive removal in small and shallow sites represent an alternative approach to estimate absolute snail densities. This is further confirmed by the fact that the catching probability of $B$. pfeifferi was well above 0.3 , therefore this method can be considered a reliable means for total density estimates (Krebs 1993).

It was emphasised by Woolhouse and Chandiwana (1989) that precise information on the spatial distribution of intermediate host snails of schistosomiasis is crucial for an understanding of disease transmission and the potential of control measures, particularly also the application of focal mollusciciding. However, only a few studies have focused on microhabitat preferences of $B$. pfeifferi. Reviewing the literature, it was concluded that water temperature in stagnant waters, and current velocity in running waters are the key factors that determine the density of $B$. pfeifferi (Appleton 1978). Thomas and Tait (1984) conducted a study in a large lake in Nigeria and B. pfeifferi was most likely to be found in shallow waters close to the shoreline. Utzinger et al. (1997a) determined shallow waters (depth: $2-7 \mathrm{~cm}$ ) as preferred microhabitats for B. pfeifferi in a small perennial river in Tanzania. The present study in a small residual pond of a river also carried out in Tanzania confirmed that B. pfeifferi prefer shallow waters (depth: $0-4 \mathrm{~cm}$ ) and are most likely to be found close to the shoreline (distance: $0-40 \mathrm{~cm}$ ). In addition, it was found that $B$. pfeifferi preferred plant detritus and bedrock as dominant substrates, which is in contrast to previous findings, where no significant preferences were reported for substratum type (Utzinger et al. 1997a). 
When the spatial microhabitat preferences of B. pfeifferi were compared with the availability of microhabitats in a man-made habitat, it was found that most favourable conditions were created, by fixing a concrete slab onto the riverbed which resulted in a uniform water depth. It was interesting to note that the layer of concrete in this habitat was covered by algae, and the density of B. pfeifferi was high, confirming recent results from Odermatt (1994). In this artificial habitat, we observed the highest B. pfeifferi densities in shallow waters (depth: $0-3 \mathrm{~cm}$ ) and at distances from the shoreline between 101 and $250 \mathrm{~cm}$. There has been considerable discussion about whether concrete provides a suitable habitat for snails, especially those of medical importance. The lining of irrigation ditches and drains with concrete was proposed as a means of schistosomiasis control because such habitats would remain free from intermediate host snails. However, De Meillon et al. (1958) found intermediate host snails well stocked in large cement reservoirs and suggested that snails can, for some time, live independently of aquatic vegetation. Malek (1958) and also Watson (1958) noticed that cemented canals are likely to become covered with a layer of silt which then provides a good ground for algae growth and consequently allows the establishment and reproduction of intermediate host snails. However, the coverage of a silt layer depends to some extent on the water velocity patterns.

Both habitats in the present study were also inhabited by $L$. natalensis and densities were even higher than those of $B$. pfeifferi. This observation confirms previous reports from different geographical settings where a positive association between B. pfeifferi and L. natalesis was documented (Dennis et al. 1983, Thomas \& Tait 1984, Madsen et al. 1988). However, no previous attempts were made to compare habitat preferences by these two snail species on the microhabitat level and our study was probably the first that tried to do this. We observed microhabitat preferences that differed significantly between B. pfeifferi and L. natalensis, as the former was found in slightly deeper water.

We conclude that in small aquatic habitats of a reduced size, visible identification and hand collecting of snails is feasible. Sampling based on repeated removal of aquatic snails enables the total densities to be estimated. However, hatchling snails may be underestimated. Structural habitat changes require baseline data on the microhabitat preferences of intermediate host snails of schistosomiasis in nearby natural habitats, in order to assess the suitability of such man-made habitats for later colonisation of snails. Such information will make it possible to give more objective advice to engi- neers on the feasibility and efficacies of potential control measures. Consequently, proposed structural habitat changes might be modified, so that the likelihood of establishing new snail habitats contributing to the spread of schistosomiasis, might be reduced.

\section{ACKNOWLEDGEMENTS}

To L Mkomange for excellent assistance in the field. To Dr DS Brown and Mrs JM Jenkins for useful suggestions on the manuscript. Research clearance was obtained from the Medical Research Council Committee of the National Institute of Medical Research (Director General Prof. WL Kilama) through the Tanzanian Commission for Science and Technology. J Utzinger was supported by the Swiss Agency for Development and Cooperation.

\section{REFERENCES}

Appleton CC 1978. Review of literature on abiotic factors influencing the distribution and life cycles of bilharziasis intermediate host snails. Malacol Rev 11: $1-25$.

Betterton C 1984. Ecological studies on the snail hosts of schistosomiasis in the South Chad Irrigation Project Area, Borno State, Northern Nigeria. J Arid Environ 7: 43-57.

Betterton C, Ndifon GT, Bassey SE, Tan RM, Oyeyi T 1988. Schistosomiasis in Kano State, Nigeria. I: Human infections near dam sites and the distribution and habitat preferences of potential snail intermediate hosts. Ann Trop Med Parasitol 82: 561-570.

Bovee KD 1982. A Guide to Stream Habitat Analysis Using the Instream Flow Incremental Methodology, FWS/OBS-82/26, U.S. Fish and Wildlife Service, Fort Collins, Colorado, 248 pp.

Brown DS 1994. Freshwater Snails of Africa and their Medical Importance, 2nd. ed., Taylor \& Francis Ltd, London, 609 pp.

De Graaf DA, Bain LH 1986. Habitat use by and preferences of juvenile Atlantic salmon in two Newfoundland rivers. Trans Am Fish Soc 115: 671-681.

De Meillon B, Frank GH, Allanson BR 1958. Some aspects of snail ecology in South Africa. Bull WHO 18: 771-783.

Dennis E, Vorkpor P, Holzer B, Hanson A, Saladin B, Saladin K, Degrémont A 1983. Studies on the epidemiology of schistosomiasis in Liberia: the prevalence and intensity of schistosomal infections in Bong County and the bionomics of the snail intermediate hosts. Acta Trop 40: 205-229.

Freyvogel TA 1960. Einige meteorologische Daten aus Südtanganyika. Acta Trop 17: 365-374.

Fritsch M 1993. Environmental Management for Schistosomiasis Control. River Flushing - A Case Study in Namwawala, Kilombero District, Tanzania, Verlag der Fachvereine, Zürich, 210 pp.

Hunter JM, Rey L, Chu KY, Adekolu-John EO, Mott KE 1993. Parasitic Diseases in Water Resources Development: The Need for Intersectoral Negotiation, World Health Organization, Geneva, 152 pp.

Jätzold R, Baum E 1968. The Kilombero Valley (Tanza- 
nia): Characteristic Features of the Economic Geography of a Semihumid East African Flood Plain and its Margins, Afrikastudien No. 28, Weltforum Verlag, München, $147 \mathrm{pp}$.

Krebs CJ 1993. Ecology: The Experimental Analysis of Distribution and Abundance, 4th. ed., Harper Collins, New York, $801 \mathrm{pp}$.

Lengeler C, De Savigny D, Mshinda H, Mayombana C, Tayari S, Hatz C, Degrémont A, Tanner M 1991. Community-based questionnaires and health statistics as tools for the cost-efficient identification of communities at high risk of urinary schistosomiasis. Int J Epidemiol 20: 796-807.

Madsen H, Christensen NØ 1992. Intermediate hosts of schistosomes: ecology and control. Bull Soc Vector Ecol 17: 2-9.

Madsen H, Daffalla AA, Karoum KO, Frandsen F 1988. Distribution of freshwater snails in irrigation schemes in the Sudan. J Appl Ecol 25: 853-866.

Malek AE 1958. Factors conditioning the habitat of bilharziasis intermediate hosts of the family Planorbidae. Bull WHO 18: 785-818.

Marti HP 1986. Field observations on the population dynamics of Bulinus globosus, the intermediate host of Schistosoma haematobium in the Ifakara area, Tanzania. J Parasitol 72: 119-124.

Marti HP, Tanner M, Degrémont AA, Freyvogel TA 1985. Studies on the ecology of Bulinus globosus, the intermediate host of Schistosoma haematobium in the Ifakara area, Tanzania. Acta Trop 42: 171187.

Mc Cullough FS 1972. The distribution of Schistosoma mansoni and S. haematobium in East Africa. Trop Geog Med 24: 199-207.

Odermatt P 1994. Comparative Investigations on the Population Dynamics of Bulinus globosus (Morelet, 1866) and Biomphalaria pfeifferi (Krauss, 1848) (Gastropoda; Planorbidae) with Special Regard to the Assessment of High Risk Areas for the Transmission of Intestinal Schistosomiasis, PhD thesis, University of Basel, Basel, 195pp.

Pervilhac C, Mshinda H, Utzinger J, Booth M, Tanner M 1998. Experiences with a multi-sectorial operation research programme for control of schistosomiasis in a Tanzanian district. Afr J Health Sci 5: 153-161.

Seber GAF, Le Cren ED 1967. Estimating population parameters from catches large relative to the population. J Anim Ecol 36: 631-643.

Smith T, Charlwood JD, Takken W, Tanner M, Spiegelhalter DJ 1995. Mapping the densities of malaria vectors within a single village. Acta Trop 59: 1-18.
Sokal RR, Rohlf FJ 1981. Biometry, 2nd. ed., Freeman, New York, 859 pp.

Sturrock RF 1993. The intermediate hosts and host-parasite relationships. In P Jordan, G Webbe, RF Sturrock (eds), Human Schistosomiasis, CAB International, Wallingford, p. 33-85.

Sutherland WJ 1996. Ecological Census Techniques. A Handbook, Cambridge University Press, Cambridge, $336 \mathrm{pp}$.

Thomas JD, Tait AI 1984. Control of the snail hosts of schistosomiasis by environmental manipulation: a field and laboratory appraisal in the Ibadan area, Nigeria. Phil Trans R Soc London, B 305: 201-253.

Upatham ES, Koura M, Ahmed MD, Awad AH 1981. Studies on the transmission of Schistosoma haematobium and the bionomics of Bulinus $(P h$. abyssinicus in the Somali Democratic Republic. Ann Trop Med Parasitol 75: 63-69.

Utzinger J, Mayombana C, Smith T, Tanner M 1997a. Spatial microhabitat selection by Biomphalaria pfeifferi in a small perennial river in Tanzania. Hydrobiologia 356: 53-60.

Utzinger J, Mayombana C, Mez K, Tanner M 1997b. Evaluation of chemical and physical-morphological factors as potential determinants of Biomphalaria pfeifferi (Krauss, 1848) distribution. Mem Inst Oswaldo Cruz 92: 323-328.

Watson JM 1958. Ecology and distribution of Bulinus truncatus in the Middle East with comments on the effect of some human activities in their relationship to the snail host on the incidence of bilharziasis haematobia in the Middle East and Africa. Bull WHO 18: 833-894.

Webbe G, Jordan P 1982. Control. In P Jordan, G Webbe (eds) Schistosomiasis - Epidemiology, Treatment and Control, William Heinemann Medical Books Ltd, London, p. 293-349.

WHO 1993. The Control of Schistosomiasis: Second Report of the WHO Expert Committee, World Health Organization, Geneva, WHO Technical Report Series, No. 830, 86 pp.

Woolhouse MEJ 1992. Population biology of the freshwater snail Biomphalaria pfeifferi in the Zimbabwe highveld. J Appl Ecol 29: 687-694.

Woolhouse MEJ, Chandiwana SK 1989. Spatial and temporal heterogeneity in the population dynamics of Bulinus globosus and Biomphalaria pfeifferi and in the epidemiology of their infection with schistosomes. Parasitology 98: 21-34.

Zumstein A 1983. A study of some factors influencing the epidemiology of urinary schistosomiasis at Ifakara (Kilombero District, Morogoro Region, Tanzania). Acta Trop 40: 187-204. 